\title{
EARLY ORDOVICIAN BIVALVE RADIATIONS AND THEIR CAUSE
}

COPE, John C.W., Department of Earth Sciences, University of Wales Cardiff, PO Box 914, Cardiff CF1 3YE, United Kingdom.

The early Ordovician saw an explosive evolution of bivalves on the peri-Gondwanan shelves. Known pre-Ordovician bivalves are limited to early Cambrian occurrences of the minute genera Fordilla and Pojetaia. In the early Ordovician bivalves suddenly increased in size, diversity and abundance. A new fauna shortly to be described from the early Arenig of South Wales describes 20 species belonging to 18 genera and represents some 60 per cent of the known early Arenig bivalve faunas; it includes the earliest solemyoids, cyrtodontoids, pterioids and anomalodesmatans, and shows that the primary bivalve diversification occurred suddenly in the early Ordovician. This explosive radiation can be correlated with the evolution of the feeding gill in bivalves.

Investigation of the mechanics of the hinge of Ordovician palaeotaxodonts bivalves has shown that they include one group in which the hinge operated in a different way from that of other palaeotaxodonts. This modification can be correlated with the evolution of the filibranch gill. Since all extant palaeotaxodonts have protobranch gills, it has been tacitly assumed that all fossil forms had similar gills. The recognition that some Ordovician palaeotaxodonts had filibranch grade gills removes one of the major obstacles to understanding the early diversification of the Class. It is now possible to identify the primary evolutionary pathways of the principal bivalve groups and to establish the Ordovician origins of many shell microstructural types through a parsimonious analysis of the origins of subsequent bivalve lineages. 